06,13

\title{
Морфология поверхности, микроструктура и пьезоэлектрический отклик перовскитовых островков в тонких пленках цирконата-титаната свинца
}

\author{
(С) И.П. Пронин ${ }^{1,2}$, Е.Ю. Каптелов ${ }^{1,2}$, С.В. Сенкевич ${ }^{1,2}$, Д.А. Киселев ${ }^{2,3}$, В.В. Осипов ${ }^{1}$, В.П. Пронин \\ ${ }^{1}$ Физико-технический институт им. А.Ф. Иоффре, \\ Санкт-Петербург, Россия \\ ${ }^{2}$ Российский государственный педагогический университет им. А.И. Герцена, \\ Санкт-Петербург, Россия \\ ${ }^{3}$ Национальный исследовательский технологический университет „МИСиС“, \\ Москва, Россия \\ E-mail: Petrovich@mail.ioffe.ru
}

Поступила в Редакцию 16 июля 2019 г.

В окончательной редакции 16 июля 2019 г.

Принята к публикации 25 июля 2019 г.

Исследованы особенности микроструктуры и пьезоэлектрического отклика перовскитовых островков в матрице пирохлорной фазы в тонких пленках цирконата-титаната свинца, сформированных методом высокочастотного магнетронного распыления. Выявлена радиальная неоднородность морфологии поверхности островков и пьезоотклика. Обсуждается роль двумерных механических напряжений, действующих на тонкую пленку со стороны кремниевой подложки.

Ключевые слова: высокочастотное магнетронное распыление, тонкие пленки цирконата-титаната свинца, перовскитовые островки, силовая микроскопия пьезоотклика

DOI: $10.21883 /$ FTT.2019.12.48556.13ks

\section{1. Введение}

Тонкие пленки цирконата-титаната свинца $\mathrm{Pb}\left(\mathrm{Zr}_{1-x} \mathrm{Ti}_{x}\right) \mathrm{O}_{3}$ (или $\left.\mathrm{PZT}\right)$ являются базовыми материалами для создания на их основе элементов неразрушаемой памяти, устройств микроэлектромеханики (МЭМС) и ИК-техники, мультиферроиков и ряда других приложений [1-5]. В большинстве случаев максимально востребованными являются составы, соответствующие области морфотропной фазовой границы (МФГ), разделяющей тетрагональную и ромбоэдрическую модификации сегнетоэлектрической фазы, где диэлектрическая проницаемость и электромеханические коэффициенты достигают максимальных значений [6-7]. Для МЭМС устройств крайне желательно иметь тонкие пленки, в которых макроскопическая поляризация (или самополяризация), близкая по значению к величине спонтанной поляризации, была бы сформирована в процессе их изготовления, что позволяет избежать последующей поляризационной процедуры [8-11]. При использовании в качестве подложки кремниевой пластины реализация этой задачи затруднена из-за различия в коэффициентах линейного расширения пленки PZT и подложки. Это приводит к возникновению двумерных растягивающих напряжений, действующих на пленку со стороны подложки, к переориентации вектора поляризации в направлении, коллинеарном с плоскостью подложки и, как следствие, к уменьшению величины самополяризации, и, значит, пьезоотклика тонкой пленки [12-14].
В ряде работ было показано, что пьезоотклик тонких пленок возрастает при уменьшении характерного поперечного размера перовскитовой области [15-16]. Так, авторами [15] в эпитаксиальных пленках, сформированных на проводящей подложке легированного ниобием титаната стронция $\mathrm{SrTiO}_{3}$, обнаружено резкое увеличение величины пьезомодуля при уменьшении поперечных размеров ниже $200 \mathrm{~nm}$. Причиной такого увеличения сигнала связывается с уменьшением количества $a$-доменов. В работе [16] уменьшение поперечного размера островков перовскитовой фазы (от $1 \mu \mathrm{m}$ до $200 \mathrm{~nm}$ ) в тонких пленках феррита висмута $\mathrm{BiFeO}_{3}$, сформированных на подложке алюмината лантана $\mathrm{LaAlO}_{3}$, приводило к изменению фазового состояния тонкого слоя от тетрагональной к ромбоэдрической модификации сегнетоэлектрической фазы и резкому увеличению пьезоэлектрического отклика. Авторы связывают наблюдаемые эффекты с релаксацией механических напряжений, действующих на пленку со стороны подложки. Целью настоящей работы являлось изучение влияния размера перовскитовых островков в пирохлорной матрице в тонких пленках PZD на морфологию поверхности островков и их пьезоэлектрический отклик.

\section{2. Подготовка образцов и методы исследования}

Тонкие пленки PZT приготавливались двухстадийным методом высокочастотного магнетронного распы- 
ления [17]. В качестве мишени использовалась керамическая мишень $\mathrm{Pb}\left(\mathrm{Zr}_{1-x} \mathrm{Ti}_{x}\right) \mathrm{O}_{3}$ состава $x=0.46$, соответствующего области МФГ. Для компенсации потерь свинца при отжиге в мишень добавлялось $10 \mathrm{~mol} \%$ избытка оксида свинца $(\mathrm{PbO})$. В качестве подложки использовалась платинированная кремниевая пластина $\left(\mathrm{Pt} / \mathrm{TiO}_{2} / \mathrm{SiO}_{2} / \mathrm{Si}\right)$. Толщина осажденных слоев составляла $\sim 500 \mathrm{~nm}$. В процессе последующего отжига на воздухе при $T_{\mathrm{ann}}=530-580^{\circ} \mathrm{C}$ происходила частичная или полная кристаллизация фазы перовскита по площади образцов.

Фазовый контроль осуществлялся с помощью рентгенодифракционного метода $\theta-2 \theta$ (ДРОН-7) и оптической микроскопии (Nikon Eclipse LV150). Микроструктура исследовалась методом растровой электронной (EVO-40, Carl Zeiss) и атомно-силовой микроскопии (ACM). Для определения вертикальной компоненты пьезоотклика использовался метод силовой микроскопии пьезоотклика (CMП, атомно-силовой микроскоп MFP-3D SA, Asylum Research). Измерения проводились в контактной моде при приложении на кантилевер переменного напряжения величиной $5 \mathrm{~V}$ на частоте $50 \mathrm{kHz}$. Площадь сканируемой поверхности не превышала $60 \times 60 \mu \mathrm{m}$.

\section{3. Результаты экспериментов и их обсуждение}

Изображения морфологии и пьезоэлектрического отклика отдельного перовскитового островка представлены на рис. 1. Перовскитовый островок круглой формы диаметром $\sim 20 \mu \mathrm{m}$, выросший в процессе высокотемпературного отжига в матрице низкотемпературной пирохлорной фазы, характеризовался отчетливым морфологическим контрастом. Его усадка при фазовой трансформации пирохлор-перовскит составляла 2-3\% (рис. 1,a). Эта усадка определяется большей кристаллической плотностью структуры перовскита по сравнению с более „рыхлой“ структурой пирохлора. Более отчетливым контрастом выделялся сигнал пьезоотклика перовскитового островка на фоне окружающей его неполярной матрицы пирохлорной фазы (рис. 1,b). Наличие сигнала пьезоотклика перовскитового островка свидетельствует о наличии макроскопической поляризации (т.е., самополяризации), вектор которой ориентирован в направлении нижнего интерфейса пленки. Предполагается, что появление макроскопической поляризации (самополяризации) вызвано действием отрицательного объемного заряда, локализованного вблизи нижнего интерфейса пленки PZT $[8,10,14,18]$. Для определения степени заполяризованности островка к его половинкам методом СМП прикладывалось поляризующее напряжение положительной и отрицательной полярности (рис. 1,c). Сравнение сигналов (рис. $1, b$ и $c$ ) показало, что степень самополяризации составляла $\sim 40-45 \%$ от величины остаточной поляризации.

Подробное изучение перовскитовых островков выявило ряд особенностей морфологии их поверхности, в том числе, в области межфазной границы пирохлорперовскит, а также распределения пьезоотклика по площади островков (рис. 2). Рис. 2, $a, b$ показывает сложную
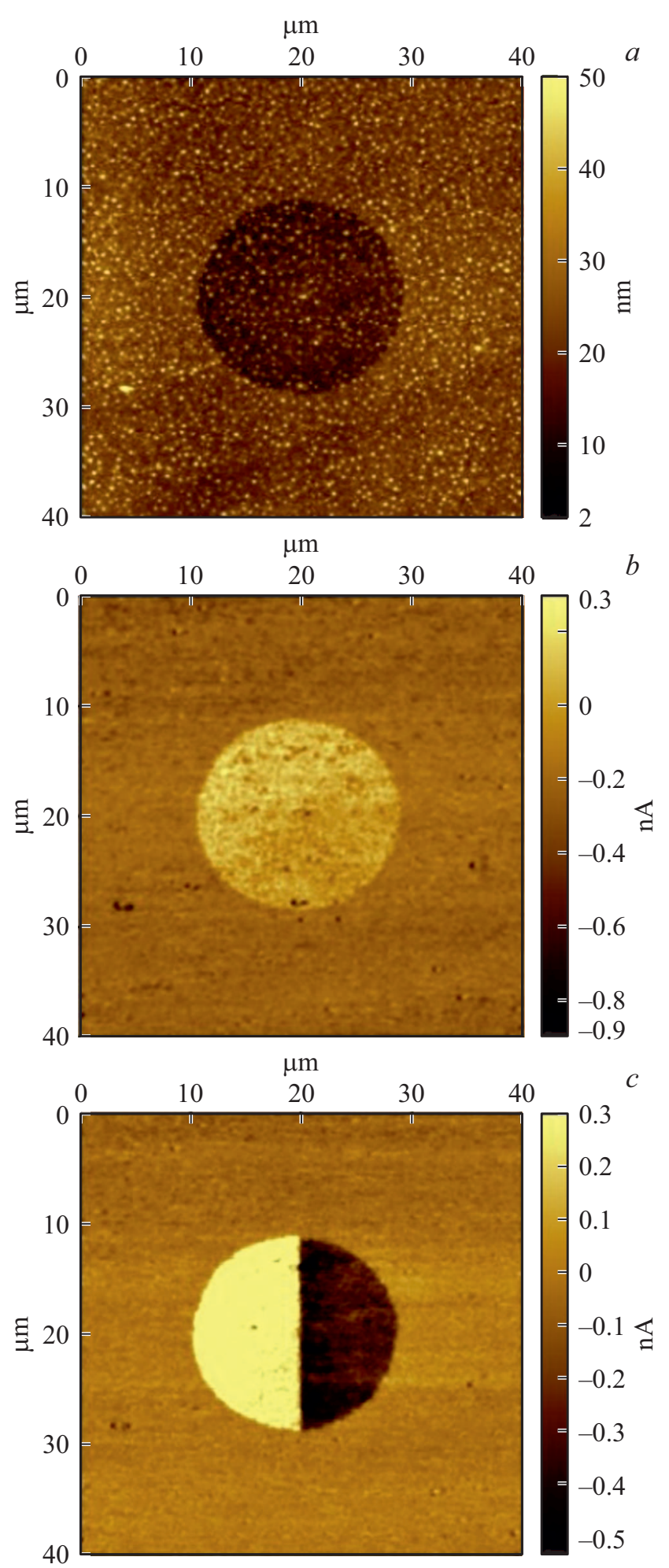

Рис. 1. АСМ- и СМП-изображения сферолитового островка перовскита в пирохлорной матрице: топография поверхности $(a)$, пьезоэлектрический отклик $(b)$, пьезоэлектрический отклик после приложения электрического поля $(c)(+25 \mathrm{~V}-$ светлая область, $-25 \mathrm{~V}-$ темная область). 

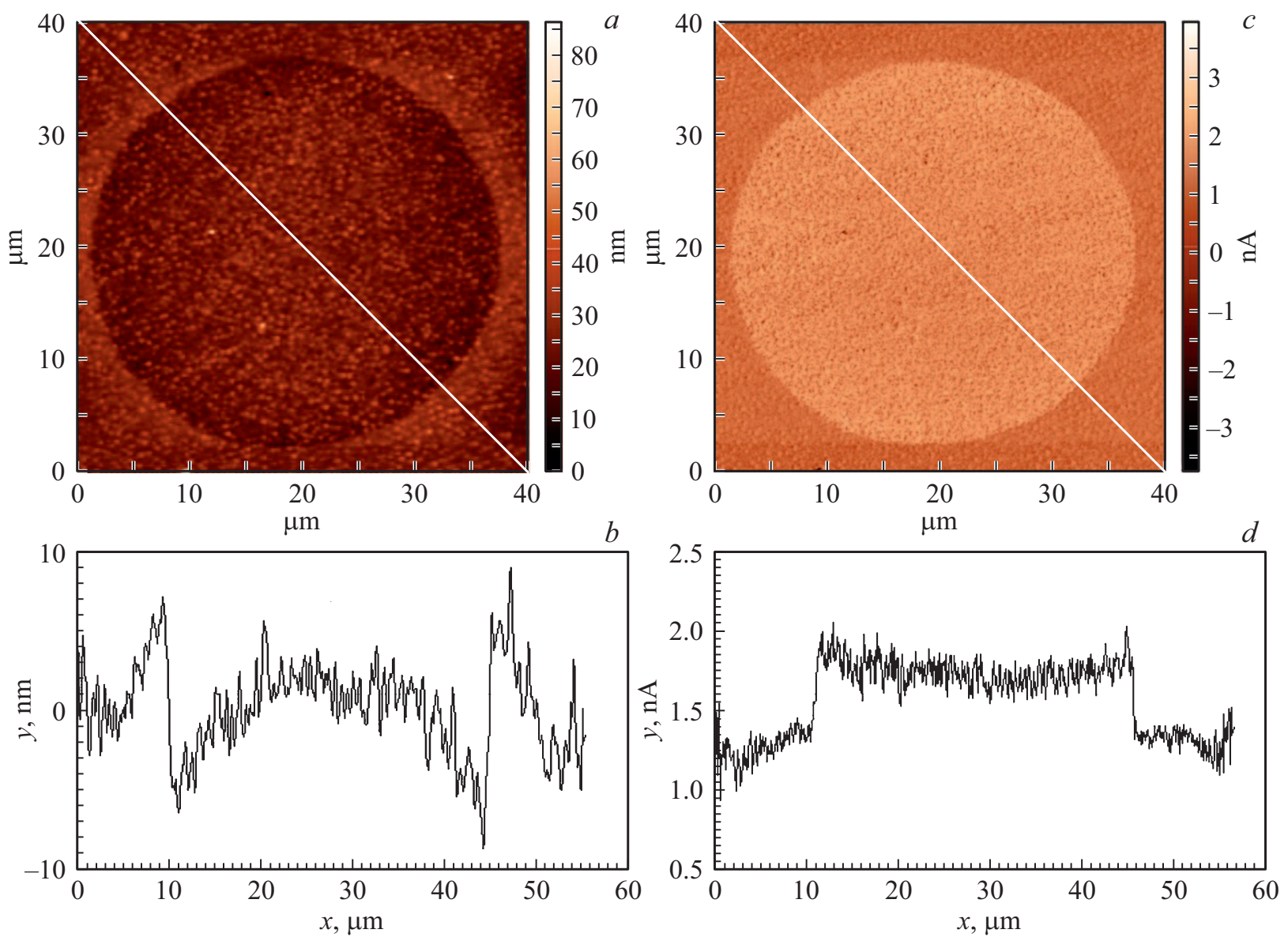

Рис. 2. АСМ-изображения перовскитового островка $(a)$, профиль поверхности островка по линии $(b)$, пьезоэлектрический отклик островка $(c)$ и профиль пьезоэлектрического отклика по линии $(d)$.

морфологическую конфигурацию фазовой границы при твердотельной трансформации пирохлор-перовскит. Она заключается в том, что толщина пирохлорного слоя на границе увеличивается (на $\sim 2 \%$ ), затем при переходе в фазу перовскита происходит резкая усадка материала (около $3 \%$ ), после чего толщина перовскитового островка увеличивается к его центру. С учетом более ранних исследований границ раздела подобных структур, в которых фазовая трансформация пирохлор-перовскит сопровождалась увеличением пористости межфазной границы $[17,19]$, можно предположить, что и в данном случае происходит образование пористой пограничной области, в которой происходит релаксация механических напряжений, вызванная различием плотностей фаз. При этом остальная часть островка находится под действием радиальных растягивающих механических напряжений.

На рис. 2, $c$ представлен пьезоотклик перовскитового островка, а на рис. $2, d-$ его профиль по выделенной линии. Хорошо видно, что максимальная величина пьезоотклика наблюдается вблизи межфазной границы пирохлор-перовскит (в пирохлорной фазе сигнал пьезоотклика отсутствует). Можно полагать, что подобное распределение связано, с одной стороны, с действием на островок растягивающих сил со стороны подложки, разворачивающих вектор поляризации в направлении, мак- симально близком к плоскости подложки, с другой с релаксацией напряжений на межфазной границе, в результате чего действие растягивающих сил на границе

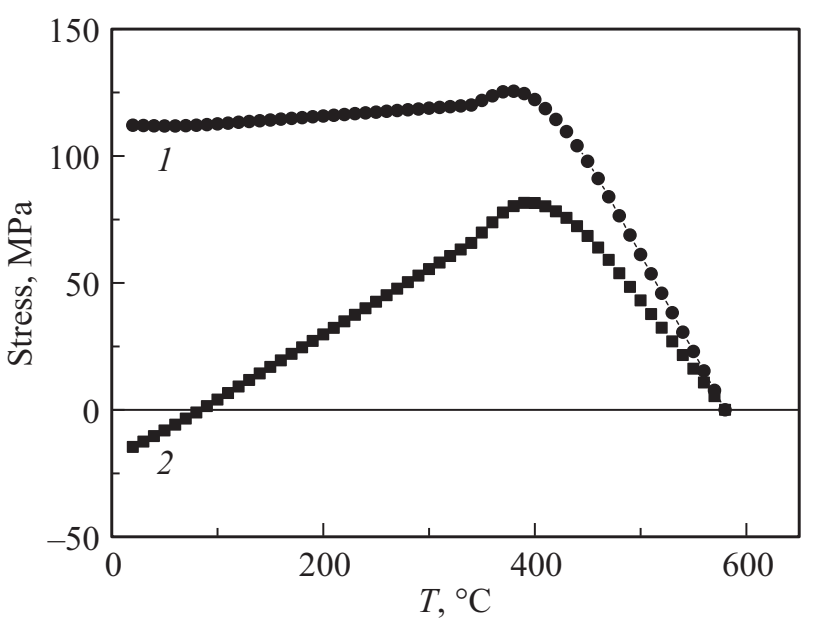

Рис. 3. Расчетные механические напряжения, действующие на пленку PZT со стороны кремниевой подложки (кривая 1) и ситалловой подложки (кривая 2), у которой температурный коэффициент линейного расширения сравним с аналогичным коэффициентом тонкой пленки. 

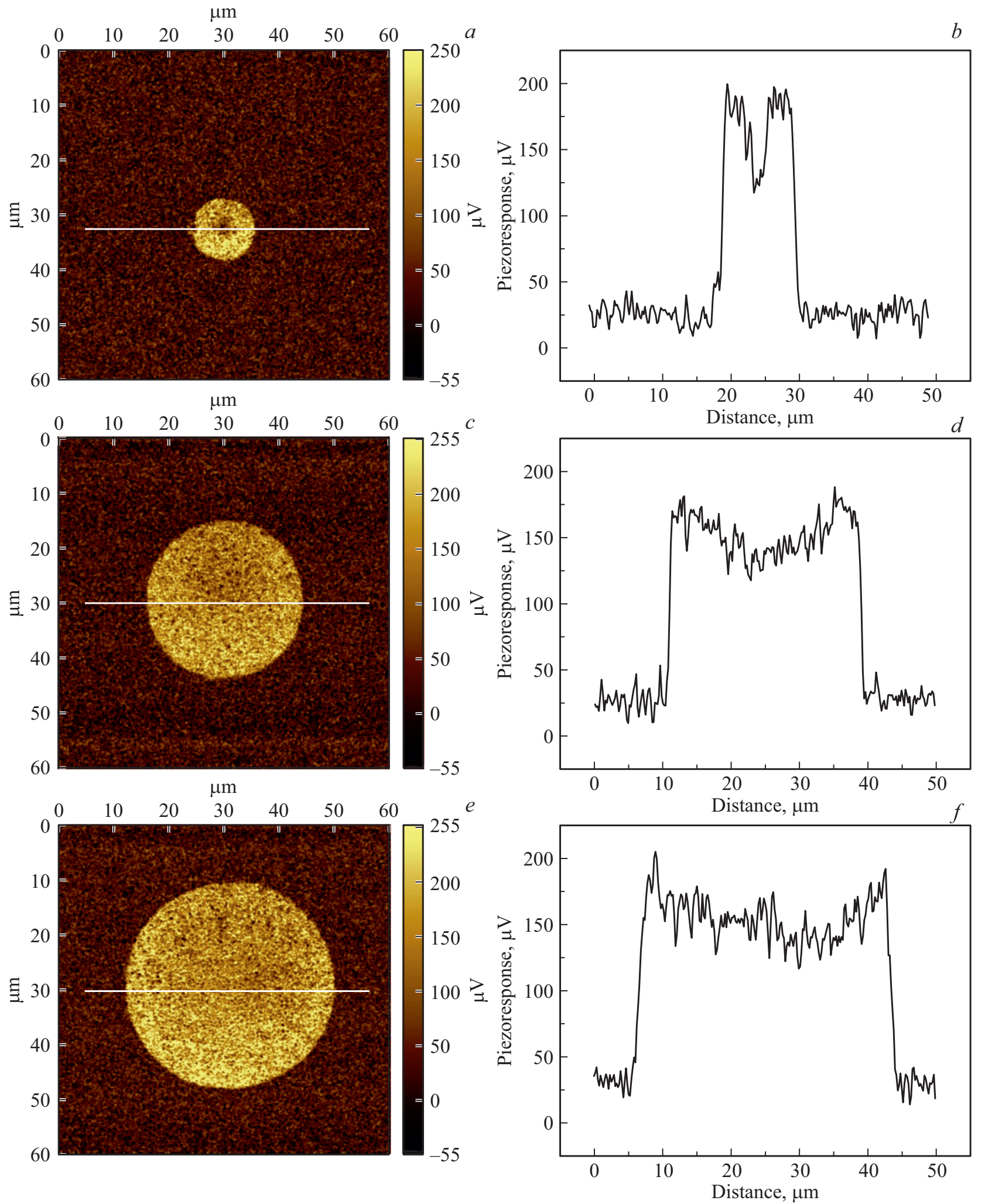

Рис. 4. СМП-изображения $(a, c, e)$ и профили пьезоэлектрического отклика $(b, d, f)$ перовскитовых островков различного диаметра.

минимизируется, а самополяризация - возрастает. В качестве подтверждения этого предположения на рис. 3, кривая 1 приведено расчетное изменение величины двумерных механических напряжений, действующих на тонкий слой PZT со стороны кремниевой подложки, при изменении температуры (методика расчета см. в работе [14]). Из представленной зависимости видно, что при комнатной температуре на слой PZT действу- 
ют растягивающие механические напряжения величиной $\sim 110 \mathrm{MPa}$.

Исследования пьезоотклика островков показали, что радиальная неоднородность сигнала зависела от линей-
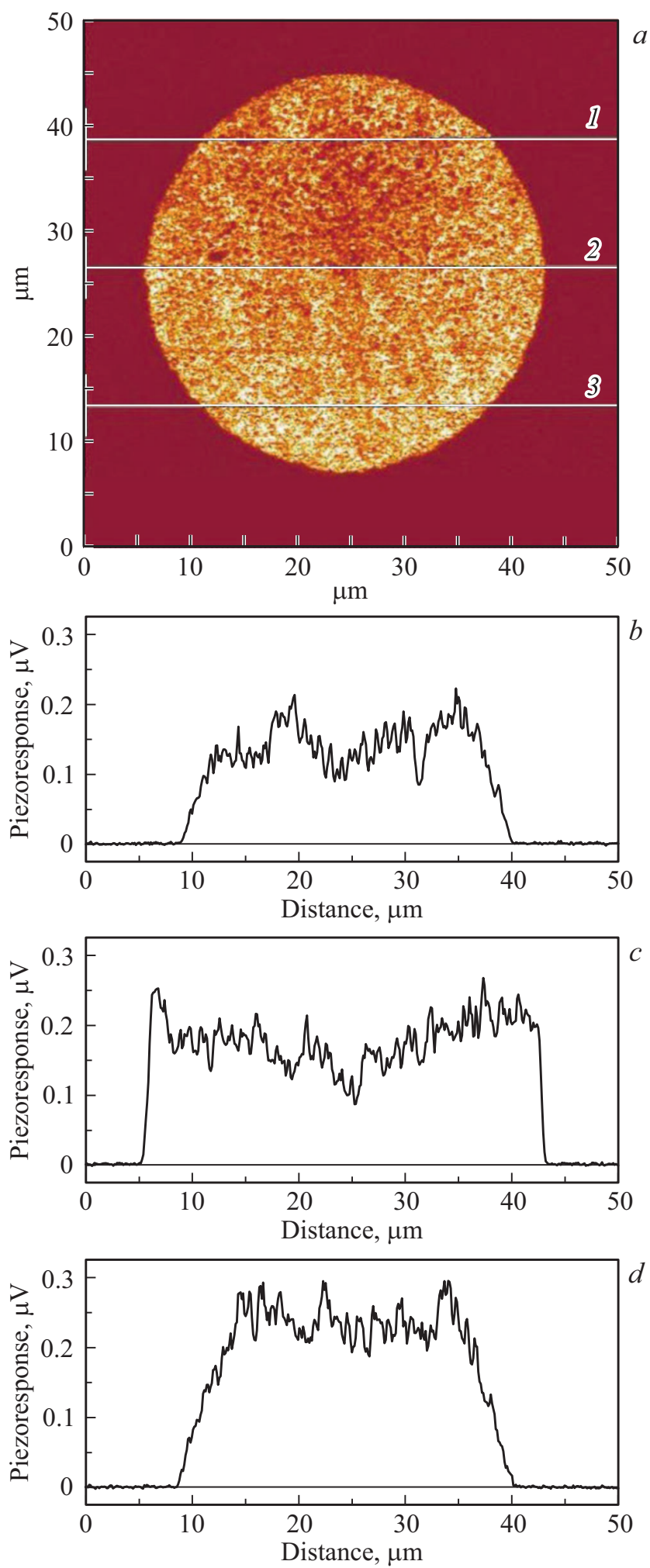

Рис. 5. СМП-изображение пьезоэлектрического отклика островка перовскита в пирохлорной матрице и его профили вдоль линий. ных размеров, более заметно проявляясь в островках небольшого размера, диаметром $\sim 10 \mu \mathrm{m}$ (рис. 4, $a-b)$, нежели в крупных, диаметром 25-35 $\mu \mathrm{m}$ (рис. 4,c-f). Величины пьезооткликов в этих островках вблизи интерфейсов с фазой пирохлора и в центральной области незначительно отличались друг от друга, при этом величина сигнала в центре островков была ниже в 1.5-1.7 раза меньше, чем на периферии. Как видно, по мере уменьшения линейного размера островков изменяется соотношение между площадью интерфейсных областей (где происходит релаксация механических напряжений) и центральной областью (где на островок действуют растягивающие напряжения). Это приводит к тому, что интегральный пьезоотклик островка существенно превышает соответствующий сигнал от сплошной перовскитовой пленки, в которой достаточно однородный по площади пьезоэлектрический отклик не превышает величину, характерную для сигнала от центральной части островка.

Таким образом, результаты, представленные на рис. 2 и 4, говорят о том, что в условиях сильных растягивающих напряжений, действующих на тонкий слой PZT, со стороны кремниевой подложки, максимальный пьезоотклик достигается при формировании островковой перовскитовой структуры.

Изучение пьезоотклика перовскитовых островков относительно больших размеров выявило не только радиальную неоднородность сигнала, но и неоднородность по площади. Об этом свидетельствуют профили трех срезов пьезоотклика, представленных на рис. $5, b-d$. Подобная неоднородность может являться следствием как развития доменной структуры в островках большого диаметра, так и неравномерного распределения объемного заряда по площади островка.

\section{4. Выводы}

На основании проведенных исследований микроструктуры и свойств самополяризованных островковых и сплошных тонких пленок PZT, сформированных на платинированной кремниевой подложке при вариации температуры их синтеза, показано, что морфология поверхности и пьезоотклик отдельных перовскитовых островков характеризуются сильной радиальной неоднородностью, которая усиливается при уменьшении линейного размера островков. Наиболее вероятной причиной обнаруженных неоднородностей является релаксация механических напряжений в области островков, прилегающих к границе их раздела с пирохлорной матрицей. Сделан вывод о том, что для повышения пьезоотклика тонких пленок PZT целесообразно использовать их в виде островковой конфигурации. Предполагается, что при использовании подложек, у которых температурный коэффициент линейного расширения будет превышать аналогичный параметр для тонких слоев PZT (рис. 3, кривая 2), величина самополяризации перовскитовых островков будет выше, а степень радиальной неоднородности заметно уменьшится. 


\section{Финансирование работы}

Работа выполнена при частичной поддержке в рамках проектной части гос. задания, проект № 16.2811.2017/4.6.

Исследования методами сканирующей зондовой микроскопии выполнены при финансовой поддержке Министерства науки и высшего образования РФ на оборудовании ЦКП „Материаловедение и металлургия“ НИТУ „МИСиС“ (проект № 11.9706.2017/7.8).

\section{Конфликт интересов}

Авторы заявляют, что у них нет конфликта интересов.

\section{Список литературы}

[1] К.А. Воротилов, В.М. Мухортов, А.С. Сигов. Энергоатомиздат, М. (2011). 175 с.

[2] D.L. Polla. Microelectron. Eng. 29, 51 (1995).

[3] N. Izyumskaya, Y.-I. Alivov, S.-J. Cho, H. Morkoç, H. Lee, Y.-S. Kang. Critical Rev. Solid State Mater. Sci. 32, 111 (2007).

[4] W. Eerenstein, N.D. Mathur, J.F. Scott. Nature 442, 759 (2006).

[5] J.-S. Yang, Y.-S. Kang, I.-Y. Kang, S.-M. Lim, S.-J. Shin, J.-W. Lee, K.-H. Hur. IEEE Transact. ultrason. Ferroelectr. Frequency Control 64, 617 (2017).

[6] Б. Яффе, У. Кук, Г. Яффе. Пьезоэлектрическая керамика. Мир, М. (1974). 288 с.

[7] Yu. Xu Ferroelectric materials and their applications. N. Holland-Amsterdam-London-N. Y.-Tokyo (1991). 391 p.

[8] R. Bruchhaus, D. Pitzer, M. Schreiter, W. Wersing. J. Electroceram. 3, 151 (1999).

[9] Sh. Sun, Y.-M. Wang, P.A. Fuierer, B.A. Tuttle. Integrated Ferroelectrics 23, 25 (1999).

[10] В.В. Осипов, Д.А. Киселев, Е.Ю. Каптелов, С.В. Сенкевич, И.П. Пронин. ФТТ 57, 1748 (2015).

[11] E. Khomyakova, M. Sadl, H. Ursic, J. Daniels, B. Malic, A. Bencan, D. Damjanovic, T. Rojac. ACS Appl. Mater. Interfaces 8, 19626 (2016).

[12] T. Ogawa, A. Senda, T. Kasanami. Jpn. J. Appl. Phys. 30, 2145 (1991).

[13] K. Ijima, R. Takayama, Y. Tomita, I. Ueda. J. Appl. Phys. 60, 2914 (1986).

[14] И.П. Пронин, Е.Ю. Каптелов, А.В. Гольцев, В.П. Афанасьев. ФТТ 45, 1685 (2003).

[15] S. Bühlmann, B. Dwir, J. Baborowski, P. Muralt. Appl. Phys. Lett. 80, 3195 (2002).

[16] F. Sun, G. Tian, C. Chen, X. Deng, P. Li, Z. Chen, W. Yang, X. Gao, Z. Fan, M. Qin, M. Zeng, X. Lu, G. Zhou, D. Chen, J.-M. Liu. Ceram. Int. 44, 21725 (2018).

[17] И.П. Пронин, Е.Ю. Каптелов, С.В. Сенкевич, В.А. Климов, Н.В. Зайцева, Т.А. Шаплыгина, В.П. Пронин, С.А. Кукушкин. ФТТ 52, 124 (2010).

[18] A.L. Kholkin, K.G. Brooks, D.V. Taylor, S. Hiboux, N. Setter. Integrated Ferroelectrics 22, 525 (1998).

[19] В.П. Пронин, С.В. Сенкевич, Е.Ю. Каптелов, И.П. Пронин. ФTT 55, 92 (2013).

Редактор К.В. Емцев 